\title{
Bilateral atraumatic dislocation of the shoulder
}

\author{
Radu Mihai, John H Dixon
}

A 69 year old woman was referred to the fracture clinic with a diagnosis of anterior dislocation of left shoulder. There was no history of acute injury. The patient had a one year history of rapidly progressing, severe rheumatoid arthritis involving her hands, knees, elbows, and left hip. RA-latex reaction was positive, rheumatoid factor concentration was $320 \mathrm{IU} / \mathrm{ml}$, and her erythrocyte sedimentation rate and $\mathrm{C}$ reactive protein were constantly high (range 52-105 $\mathrm{mm} / \mathrm{hour}$ and 60-105 $\mathrm{mg} / \mathrm{l}$, respectively). She was treated with diclofenac and co-dydramol and had never been on steroids. On clinical examination there was a step deformity of both shoulders (fig 1), severe restriction of movements and palpable anteriorly dislocated humeral heads. Axillary nerve and radial pulse were normal. Radiographs confirmed anterior dislocation of both shoulders (subcoracoid) and severe destruction of the anterior rim of the glenoid (fig 2).

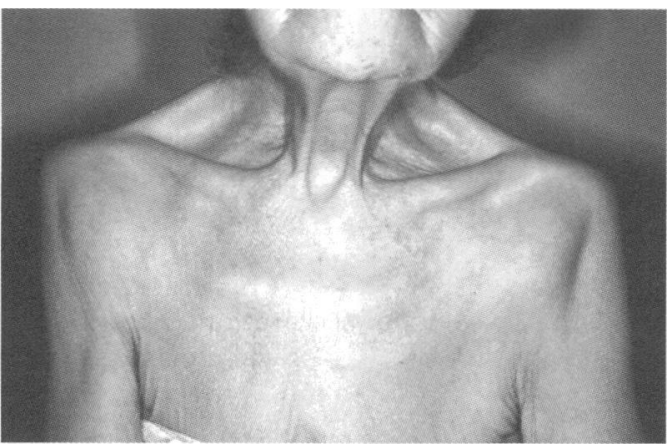

Figure 1 Classical clinical findings of anterior shoulder dislocation.

\section{Trainee (e-mail: \\ r_mihai99@hotmail.com). \\ Department of Orthopaedics, Weston General Hospital, Weston-super-Mare, Somerset BS23 4TQ R Mihai \\ J H Dixon}
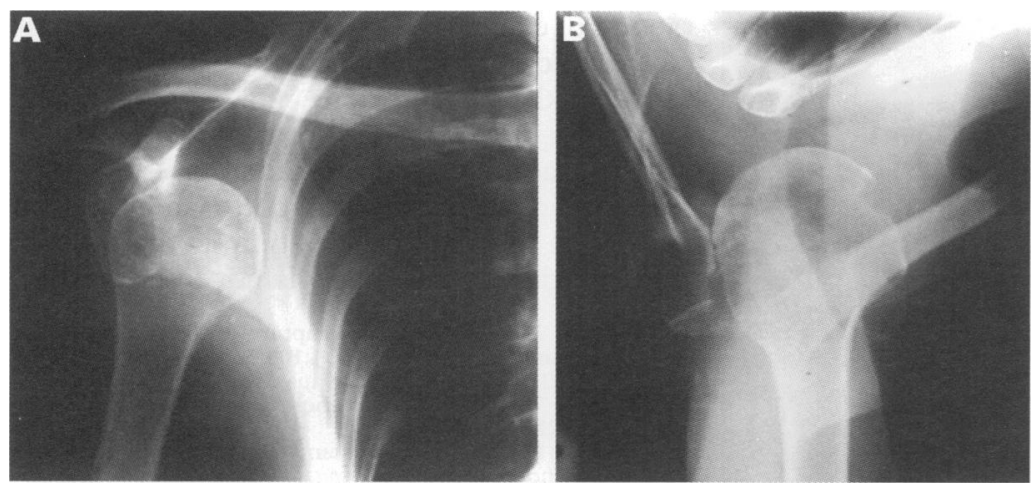

Figure 2 Axillary view radiograph showing $(A)$ anterior dislocation of the humeral head and $(B)$ severe destruction of glenoid rim.
In contrast with the classical presentation, this patient had no obvious history of trauma and no acute symptoms. After years of severe rheumatoid arthritis, she became progressively invalidated by the restriction of shoulder movements. The clinical examination was much facilitated by her slim constitution and the humeral heads could easily be seen and palpated. The key investigation was the axial radiographs that showed destructive changes of the anterior half of the glenoid in both shoulders leading to chronic dislocation.

Rheumatoid arthritis is a common chronic inflammatory disorder. The shoulder joints are involved in the majority of patients with rheumatoid arthritis $(50 \%-70 \%)$. Synovitis of the glenohumeral and acromioclavicular are frequent, but it may be difficult to distinguish inflammatory from degenerative abnormalities. ${ }^{1}$ In rheumatoid arthritis the shoulders appear both squared and raised (while in dislocation they are squared and dropped) because of upward subluxation of the humeral head as a result of dysfunction of the rotator cuff and muscle contracture. ${ }^{2}$ In patients with severe disease the surgical procedures should be limited to those that are most needed to control pain and make the patient independent. The most frequent procedure now done is total joint replacement, in which both sides of the joint are resurfaced. Glenohumeral replacement arthroplasty would have been the curative treatment for such a patient (surgical technique described in $\mathrm{Neer}^{3}$ ). Because of poor muscles the stability of such a prosthesis would have been very unlikely and therefore the long term prognosis would have been equally poor in this patient. A conservative management was adopted.

In conclusion, in a patient with atraumatic shoulder dislocations the underlying cause should be sought first. It is therefore important for junior accident and emergency doctors to recognise the condition and to refrain from attempting reduction in such patients.

1 Wollheim FA. Rheumatoid arthritis-the clinical picture. In: Maddison PJ, Isenberg DA, Woo P, et al, eds. Oxford textbook of rheumatology. Oxford: Oxford Medical Publications, 1993: 642 .

2 Paice E. Principles of examination of the musculoskeletal system. In: Maddison PJ, Isenberg DA, Woo P, et al, eds. Oxford textbook of rheumatology. Oxford: Oxford Medical Publications, 1993: 34.

3 Neer CS. Surgery of the shoulder. In: Sledge CB, Ruddy S, Harris ED, et al, eds. Arthritis surgery. Philadelphia: W B Saunders, 1994: 754-69. 